\title{
Efficacy of Minimal Volume of Articaine Local Anesthetic for Buccal Infiltration During Extraction of Maxillary and Mandibular First and Second Molars: A Prospective Study
}

Mansi Dey ${ }^{1 *}$, Monalisa Banerjee ${ }^{1}$, Daksh Goel ${ }^{1}$, Tanu Mahajan², Bibhu P Mishra ${ }^{1}$ and Shyamalendu Laskar ${ }^{3}$

${ }^{1}$ Emergency MDS, Oral and Maxillofacial Surgery, ITS Centre for Dental Studies and Research, India

${ }^{2}$ Interventional MDS, Conservative Dentistry and Endodontics, ITS Centre for Dental Studies and Research, India

${ }^{3} \mathrm{MDS}$, Oral and Maxillofacial Surgery, Index Institute of Dental Sciences, Indore, India

*Corresponding author: Dey M, MDS, Oral and Maxillofacial Surgery, ITS Centre for Dental Studies and Research, Muradnagar, Ghaziabad, Uttar Pradesh, India, Tel: 84477 53520; E-mail: shikhadey2904@gmail.com

Received: February 15, 2021; Accepted: March 20, 2021; Published: March 27, 2021

\begin{abstract}
Aim: To evaluate the efficacy of minimal volume of articaine buccal infiltration in extraction of maxillary and mandibular first and second molars.

Materials and Method: The study was conducted in the Department of Oral and Maxillofacial Surgery at ITS Centre for Dental Studies and Research, Muradnagar, Ghaziabad, Uttar Pradesh, India, from December 2019 to February 2020. A total of 60 patients were included in the study and were divided into two groups as follows: Group 1 patients who were administered articaine infiltration for the extraction of maxillary first and second molars and Group 2 patients who were administered the same local anesthetic for the extraction of mandibular first and second molars.

Result: Anesthesia of the posterior maxillary teeth was obtained using $0.5 \mathrm{ml}$ of articaine buccal infiltration alone while the posterior mandibular teeth required a supplemental lingual infiltration in all the cases.

Conclusion: $4 \%$ articaine buccal infiltration, as low as $\mathbf{0 . 5} \mathrm{ml}$ provides successful anesthesia for the extraction of maxillary molars. Palatal injection is generally not required. Buccal infiltration of the lower molars using $0.5 \mathrm{ml}$ of $4 \%$ articaine could be a good option for extraction of the mandibular posterior teeth, of course, with supplemental lingual anesthesia.
\end{abstract}

Keywords: Articaine; Anesthesia; Infiltration; Molars

Citation: Dey M, Banerjee M, Goel D, et al. Efficacy of Minimal Volume of Articaine Local Anesthetic for Buccal Infiltration During Extraction of Maxillary and Mandibular First and Second Molars: A Prospective Study. Clin Case Rep Open Access. 2021;4(1):182. 


\section{Introduction}

The era of local anesthetics began with the discovery of cocaine in 1860 [1]. Later, development of Novocain took place in 1904. Lidocaine was developed by Lofgren and Lundquist in 1942. Thereafter, many other drugs with different onset and duration of actions were introduced [1,2].

Articaine was first the first local anesthetic to be marketed in Germany in 1976 [2]. It is an amide local anaesthetic containing an ester which permits hydrolyzation in plasma by nonspecific cholinesterases, and a thiophene group that increases its liposolubility, which in turn facilitates better diffusion of the anaesthetic solution to the teeth [3-6]. Hence, the chances of failure to diffuse through hard and soft tissues are less with the use of articaine local anesthetic. Since the articaine possess both an ester and an amide linkage, the risk of overdose is also reduced. The elimination half-life of most of the amide local anaesthetics is approximately $90 \mathrm{~min}$ while that of articaine is $27 \mathrm{~min}[5,7]$.

It is not recommended to administer articaine in the form of a nerve block because of risk of paresthesia and neurotoxicity owing to its high concentration [8].

\section{Aim}

To evaluate the efficacy of minimal volume of articaine buccal infiltration in extraction of maxillary and mandibular first and second molars.

\section{Materials and Methods}

We conducted a prospective study on the patients who reported to the Department of Oral and Maxillofacial Surgery at ITS Centre for Dental Studies and Research, Muradnagar, Ghaziabad, Uttar Pradesh, India, from December 2019 to February 2020. Ethical approval was taken by the Institutional Review Board. The local anesthetic used for the extraction of maxillary and mandibular first and second molars was 4\% articaine with 1:100,000 epinephrine (Septanest;Septodont;France). A total of 60 patients were included in the study and were divided into two groups as follows:

Group 1: Patients were administered $0.5 \mathrm{ml}$ of articaine buccal infiltration for the extraction of maxillary first and second molars

Group 2: Patients were administered $0.5 \mathrm{ml}$ of articaine buccal infiltration for the extraction of mandibular first and second molars

The inclusion and exclusion criteria was follows:

Inclusion criteria:

1. Patients who needed extraction of maxillary or mandibular first or second molar

2. Patients who agreed to undergo extraction of more than one tooth in the same visit under local anesthesia.

3. Only the permanent teeth were included

4. Patients who granted informed consent 
Exclusion criteria:

1. History of allergy to local anesthetics

2. Third molars were not included

3. History of diabetes mellitus, hypertension, or renal diseases

4. Patients on central nervous system depressants including alcohol or any analgesic medication within the last 48 hours

5. Pregnant and lactating females

6. Children

7. Patients having abscess or any other lesion at the injection site

8. Teeth with grade III mobility and severe bone loss

9. Patients who were not willing to give informed consent

10. Patients unwilling to participate in the study

All the patients were explained about the procedure, and informed consent was obtained. They were administered $0.1 \mathrm{ml}$ of the anesthetic agent (intradermal allergy test) on the dorsal part of their arms and then observed for hypersensitivity reactions immediately, after $24 \mathrm{hrs}$ and after $72 \mathrm{hrs}$. None of the patients showed any immediate or delayed hypersensitivity reactions.

$3 \mathrm{ml}$ syringes along with 27-gauge needles were used to withdraw the anesthetic from $1.7 \mathrm{ml}$ cartridges of articaine, as per requirement. There was no need to use the whole cartridge for every patient. The injection sites were cleaned with sterile gauze. The lips and cheek were retracted using a dental mirror in order to apply slight tension to the tissue, and the needle inserted into the tissue at the depth of the mucobuccal fold adjacent to the tooth to be extracted. The bevel of the needle was kept towards the bone, and the syringe parallel to the longitudinal axis of the tooth using the tip of the needle inserted into the depth of the buccal vestibule. After negative observation was observed, the contents of the syringes were administered into the buccal vestibule.

Thirty seconds after the administration of anesthesia, the buccal and palatal/lingual tissues around each tooth were probed using a dental explorer.

The following data were collected for interpretation of results:

- Success of anesthesia: The anesthesia was considered to be successful only if the patient did not experience any pain during extraction.

- Onset of anesthesia: It was assessed from the time lapse between the end of the nerve block and onset of symptoms of subjective anesthesia (no pain is felt during dental therapy). A standard digital stop clock was used that calculated the time in seconds.

- Pain assessment: The pain on injection was rated on a Visual Analogue Scale. Patients were shown the scale and were asked to draw a line between 1 to 10 , according to the severity of pain.

- Duration of anesthesia: It was assessed from the time lapse between the onset of subjective symptoms of anesthesia and the termination of the effect of anesthesia. The patients were asked to inform the time at which they started experiencing pain and had to take analgesic after the effect of anesthesia had gone. The time was calculated in hours and converted into seconds. 
www.yumedtext.com | March-2021 | ISSN: 2582-5038 | https://dx.doi.org/10.46527/2582-5038.182

Statistical analysis: Data was entered and analyzed using a computer database/statistical software package (SPSS) version 16 and analyzed with descriptive statistics and one sample t test.

\section{Result}

Group 1: The mean age of the patients' was $55.80 \pm 10.38$ years. The age ranged from 36 to 72 years. Anesthesia was obtained using $0.5 \mathrm{ml}$ of articaine buccal infiltration alone and there was no need for additional palatal infiltration, except in one case that required $0.1 \mathrm{ml}$ of palatal infiltration using articaine. The mean pain on injection was $2.07 \pm 1.23$. The mean onset of action of anesthesia on the buccal side was $34.93 \pm 4.95$ seconds while that on the palatal side was $72.33 \pm 12.78$ seconds. The mean duration of anesthesia was $222.76 \pm 52.43$ seconds (TABLE 1).

Group 2: The mean age of the patients' was $54.80 \pm 9.82$ years. Anesthesia of the buccal tissues were obtained by $0.5 \mathrm{ml}$ of articaine buccal infiltration, but for the lingual tissues, additional $0.5 \mathrm{ml}$ of lingual infiltration was required. The mean pain on injection was $2.23 \pm 1.36$. The mean onset of action of anesthesia on the buccal side was $36.47 \pm 4.85$ seconds while that on the lingual side was $38.20 \pm 3.87$. The mean duration of anesthesia was 201.33 \pm 55.51 seconds (TABLE 1).

TABLE 1. Table showing age, pain on injection, onset and duration of action in the respective groups.

\begin{tabular}{|lc|c|c|c|}
\hline & $\mathbf{1}^{\text {st }}$ and $\mathbf{2}^{\text {nd }}$ molars extracted & $\mathbf{N}$ & Mean & Std. Deviation \\
\hline Age & Maxillary & 30 & 55.80 & 10.38 \\
& Mandibular & 30 & 54.80 & 9.82 \\
\hline Pain on injection & Maxillary & 30 & 2.07 & 1.23 \\
& Mandibular & 30 & 2.23 & 1.36 \\
\hline Onset of action & (Buccal side) Maxillary & 30 & 34.93 & 4.95 \\
& Mandibular & 30 & 36.47 & 4.85 \\
\hline Onset of action & (Palatal side) Maxillary & 30 & 72.33 & 12.78 \\
Onset of action & (Lingual side) Mandibular & 30 & 38.20 & 3.872 \\
\hline Duration of Action & Maxillary & 30 & 222.76 & 52.43 \\
& Mandibular & 30 & 201.33 & 55.51 \\
\hline
\end{tabular}

\section{Discussion}

The buccal infiltration is most commonly used to provide anesthesia of the individual teeth. This technique is usually applied for anesthesia of the the maxilla and the anterior mandible [9]. Infiltration anaesthesia can be successful in up to 100\% of cases in the maxilla [10]. However, the success rate for the posterior mandible has been reported to be between $48 \%$ and $76 \%$ (when using articaine) [11].

We did this prospective study to check the efficacy of $0.5 \mathrm{ml}$ of articaine buccal infiltration in the extraction of maxillary and mandibular first and second molars. Successful anesthesia was obtained using $0.5 \mathrm{ml}$ of articaine buccal infiltration for the extraction of maxillary first and second molars. Only one patient required a supplemental palatal injection of $0.1 \mathrm{ml}$ articaine for the extraction of a maxillary first molar. 
www.yumedtext.com | March-2021 | ISSN: 2582-5038 | https://dx.doi.org/10.46527/2582-5038.182

Previous studies have reported that maxillary molar extraction is possible with only buccal infiltration of articaine alone, thus eliminating the need for painful palatal injection [12-14]. However, the doses of articaine required for buccal infiltration in these studies was much higher $(1.8 \mathrm{ml}-2 \mathrm{ml})$ as compared to that in our study $(0.5 \mathrm{ml})$. Some studies have described various reasons for the failure of buccal infiltration injections in maxillary molars such as a longer root length, root divergence, pulp inflammation [15]. These were not considered in our study. Hence it is suggested that further studies be carried out with larger sample sizes using different concentrations of anesthetic agents by considering of the root length and divergence [16].

Studies have also been carried out to show the success rate of articaine buccal infiltration in mandibular first and second molars. It is difficult to provide successful anesthesia in the mandible in adults because of the thick buccal cortical bone [17]. We used $0.5 \mathrm{ml}$ of articaine to provide buccal infiltration for the extraction of mandibular molars and found that it was not sufficient to act as a substitute for inferior alveolar nerve block using $2 \%$ lidocaine. This was in accordance with the other studies which reported that a combination of both buccal and lingual infiltration is more efficient to achieve anesthesia of the lingual tissue as well, as compared to the buccal infiltration alone [18-20]. Bataineh and Alwarafi reported painless extraction of mandibular first molars after buccal and lingual infiltration anaesthesia [21]. However, the volume of articaine used for infiltration in these studies was much higher $(1.8 \mathrm{ml}-2 \mathrm{ml})$ as compared to that used in our study. El-Kholey used $1.5 \mathrm{ml}$ of articaine for buccal infiltration and $0.3 \mathrm{ml}$ for lingual [18]. We used $0.5 \mathrm{ml}$ for buccal infiltration and and another $0.5 \mathrm{ml}$ for lingual tissue and achieved successful anesthesia for painless extraction of the teeth in all the cases.

Articaine is widely available world-wide and has become practical choice for use in routine dental practices. The use of articaine is not recommended in children who are under 4 years of age because no data exists to support such use [5].

\section{Conclusion}

$4 \%$ articaine buccal infiltration, as low as $0.5 \mathrm{ml}$ provides successful anesthesia for the extraction of maxillary molars. Palatal injection is generally not required. Buccal infiltration of the lower molars using $0.5 \mathrm{ml}$ of $4 \%$ articaine could be a good option, of course, with supplemental lingual anesthesia. The ability of articaine to be effective even at such lower doses reduces the chances of developing side effects of the drug and is also cost effective. Also, it showed faster onset and long duration of action. However, further studies with larger sample size are required.

\section{Funding}

None

\section{Ethical}

The work done is in accordance with the Code of Ethics of the World Medical Association (Declaration of Helinski)

\section{Patient Consent}

Written informed consent was obtained from all patients. 


\section{Author Consent}

All authors have viewed and agreed to the submission.

\section{Conflict of Interest}

The authors declare that they do not have any conflict of interest.

\section{REFERENCES}

1. Catterall W, Mackie K. Local anesthetics. In: Hardman JG, Limbird LE, editors. Goodman \& Gilman's the pharmacological basis of therapeutics. 10th edn. New York, NY: McGraw-Hill, USA; 2001. 367-84 p.

2. Strichartz GR, Berde CB. Local anesthetics. In: Miller RD, editor. Miller's anesthesia. New York: Churchill Livingstone, USA; 2005. 573-603 p.

3. Malamed SF, Gagnon S, Leblanc D. Articaine hydrochloride: a study of the safety of a new amide local anesthetic. J Am Dent Assoc. 2001;132(2):177-85.

4. Sierra Rebolledo A, Delgado Molina E, Berini Aytis L, et al. Comparative study of the anesthetic efficacy of $4 \%$ articaine versus $2 \%$ lidocaine in inferior alveolar nerve block during surgical extraction of impacted lower third molars. Med Oral Patol Oral Cir Bucal. 2007;12(2):E139-44.

5. Katyal V. The efficacy and safety of articaine versus lignocaine in dental treatments: a meta-analysis. J Dent. 2010;38(4):307-17.

6. Snoeck M. Articaine: a review of its use for local and regional anesthesia. Local Reg Anesth. 2012;5:23-33.

7. Malamed SF, Gagnon S, Leblanc D. Efficacy of articaine: a new amide local anesthetic [see comment]. J Am Dent Assoc. 2000;131(5):635-42.

8. Hillerup S, Jensen RH, Ersbøll BK. Trigeminal nerve injury associated with injection of local anesthetics: needle lesion or neurotoxicity? J Am Dent Assoc. 2011;142:531-9.

9. Evers H, Haegerstam G. Introduction to Dental Local Anaesthesia. Fribourg: Mediglobe, Switzerland; 1990.

10. Vähätalo K, Antila H, Lehtinen R. Articaine and lidocaine for maxillary infiltration anaesthesia. Anesth Prog. 1993;40(4):114-6.

11. Kwon H, Shin Y, Cho SY, et al. Factors affecting the success rate of buccal infiltration anaesthesia in the mandibular molar region. Int Endod J. 2014;47(12):1117-22.

12. Uckan S, Dayangac E, Araz K. Is permanent maxillary tooth removal without palatal injection possible? Oral Surg Oral Med Oral Pathol Oral Radiol Endod. 2006;102(6):733-5.

13. Lima-Junior JL, Dias-Ribeiro E, de Araujo TN, et al. Evaluation of the buccal vestibule- palatal diffusion of $4 \%$ articaine hydrochloride in impacted maxillary third molar extractions. Med Oral Patol Oral Cir Bucal. 2009;14(3):E129-32.

14. Fan S, Chen WL, Yang ZH, et al. Comparison of the efficiencies of permanent maxillary tooth removal performed with single buccal infiltration versus routine buccal and palatal injection. Oral Surg Oral Med Oral Pathol Oral Radiol Endod. 2009;107(3):359-63.

15. Askari EM, Parirokh M, Nakhaee N, et al. The Effect of Maxillary First Molar Root Length on the Success Rate of Buccal Infiltration Anesthesia. J Endod. 2016;42(10):1462-6. 
16. Maljaei E, Pourkazemi M, Ghanizadeh M, et al. The efficacy of buccal infiltration of $4 \%$ articaine and PSA injection of 2\% lidocaine on anesthesia of maxillary second molars. Iran Endod J. 2017;12(3):276.

17. KhouryJN, MihailidisS, GhabrielM, et al. Applied anatomy of theptery-gomandibular space:improving the success of inferior alveolar nerve blocks. Aust Dent J. 2011;56(2):112-21.

18. Meechan JG. The use of the mandibular infiltration anesthetic technique in adults. J Am Dent Assoc. 2011;142(suppl3):19S-24S.

19. Rayati F, Noruziha A, Jabbarian R. Efficacy of buccal infiltration anaesthesia with articaine for extraction of mandibular molars: a clinical trial. Br J Oral Maxillofac Surg. 2018;56(7):607-10.

20. El-Kholey KE. Anesthetic Efficacy of $4 \%$ articaine during extraction of the mandibular posterior teeth by using inferior alveolar nerve block and buccal infiltration techniques. J Maxillofac Oral Surg. 2017;16(1):90-5.

21. Bataineh AB, Alwarafi MA. Patient's pain perception during mandibular molar extraction with articaine: a comparison study between infiltration and inferior alveolar nerve block. Clin Oral Investig. 2016;20(8):2241-50. 